\title{
Periprocedural Myocardial Injury during percutaneous coronary intervention: How can it be prevented?
}

\author{
CM Shaheen Kabir?, M Maksumul Haq2, M A Rashid', Syed Dawood Md Taimur, Md. Hasanur Rahman', Hemanta I \\ Gomes, Md. Salahuddin', Mah-Noor Jahan"
}

\begin{abstract}
Percutaneous coronary intervention (PCI) has become the predominant procedure for coronary revascularization in patients with both stable and unstable coronary artery disease (CAD), Over the past two decades, technical advances in $\mathrm{PCI}$ have resulted in a better and safer therapeutic procedure with minimal procedural complications. However, about $30 \%$ of patients undergoing elective PCI sustain myocardial infury arising from the procedure itself, the extent of which is significant enough to carry prognostic importance. The peri-procedural injury which accompanies PCI might therefore reduce some of the beneficial effects of coronary revascularization. The availability of more sensitive serum biomarkers of myocardial injury such as creatine phosphokinase MB isoenzyme (CK-MB) and Troponin I has enabled the quantification of previously undetectable myocardial injury. The identification of CAD patients at greatest risk of sustaining periprocedural myocardial injury (PMI) during $\mathrm{PCl}$ would allow targeted treatment with novel therapies capable of limiting the extent of PMI or reducing the number of patients experiencing PMI.
\end{abstract}

Keywords: Percutaneous coronary Intervention, Ischaemia, Reperfusion, Myocardial infarction.

\section{INTRODUCTION}

Percutaneous coronary intervention (PCI) has become a standard revascularization procedure for patients with coronary artery disease (CAD). ${ }^{1}$ Periprocedural myocardial injury (PMI) occurs in $5-30 \%$ of patients after PCI. ${ }^{2}$ Guidelines for the universal diagnosis of myocardial infarction (MI) recommend elevation of cardiac biomarkers above the $99^{\text {th }}$ centile upper reference limit (URL) for the confirmation of PMI if a normal baseline troponin value can be assumed. ${ }^{3}$ Elevation of more than five times the 99th centile URL is defined as a PCI-related MI (MI type $4 a){ }^{3}$ Indeed outcomes after $\mathrm{PCI}$ with very high procedural CKMB levels ( $>5 \times$ or $>8 \times$ the upper limit of normal) have prognostic implications similar to those of spontaneous acute MI. ${ }^{3}$ Any troponin elevation was associated with a significantly increased

\section{Authors' Information:}

1. Dr. C M Shaheen Kabir, MBES, MD (Card.), Registrar \& Specialist in Cardiology, Ibrahim Cardiac Hospital \& Research Institute, 122, Kazi Nazrui Islam Avenue, Shahbag, Dhaka-1000.

2. Prof. Dr. M. Maksumul Maq, MBBS, FCPS, FACC, FRCP, Head of the department of Cardiology and Senior Consultant, 122, Kazi Nazrul Islam Avenue, Shahbag, Dhaka-1000.

3. Prof. Dr. M A Rashid, Chief Executive Officer and Senior Consultant, Department of Cardiology, Ibrahim Cardiac Hospital \& Research Institute, 122, Kazi Nazrul Islam, Avenue, Shahbag, Dhaka-1000.

4. Dr. Syed Dawood Md. Taimur, MBBS, D.CARD(DU), Registrar \& Specialist, Department of Cardiology, Ibrahim Cardiac Hospital \& Research Institute, 122, Kazi Nazrul Isiam Avenue, Shahbag, Dhaka-1000.

5. Dr. Md. Hasanur Rahman, MBBS, D.CARD(DU), Associate Consuitant, Department of Cardiology, Ibrahim Cardiac Hospital \& Research Institute, 122, Kazi Nazrul Islam Avenue, Shahbag, Dhaka-1000,Tel: 9671145-47.

6. Dr. Hemanta I. Gomes, MBBS, D.CARD(DU), Associate Consultant, Department of Cardioiogy, Ibrahim Cardiac Haspitaf a Research Institute, 122, Kazi Nazrul Islam Avenue, Shahbag, Dhaka-1000,Tel: 9671145-47.

7. Dr. Md. Salahuddin, MBSS, D.CARD(BSMMU), Registrar \& Specialist, Department of Cardiofogy, Ibrahim Cardiac Hospitaf \& Research Institute, 122, Kazl Nazrul Islam Avenue, Shahbag, Dhaka-1000.

8. Dr. Mah-Noor Jahan, MBSS, DMU, Clinical Sonologist, Department of Radiology and imaging, Holy Family Red Crescent Medical College \& Hospltal, 1, Eskaton Garden Road, Dhaka-1000.

Address of Correspondance: Dr. C M Shaheen Kabir, Registrar \& Specialist, Department of Cardioiogy, Ibrahim Cardiac Hospital \& Research Institute, 122, Kazi Nazrul Islam Avenue, Shahbag, Dhaka-1000, Bangladesh.

Email: skabir67@yahoo.com, Moblie: +8801817578389. 
mortality risk. The most recent meta-analysis applied the universal definition of periprocedural MI (type 4a) using a troponin elevation of $5 \times$ the URL as the cut-off point. It included 7578 patients undergoing non-emergency PCI with normal baseline troponin levels. Troponin elevation occurred in $28.7 \%$ of the procedures and the incidence of type $4 \mathrm{a}$ MI was $14.5 \% .^{4}$ Type $4 \mathrm{a}$ MI increased the risk of major adverse cardiac events compared with those patients without troponin elevation at an average followup of about 17.7 months. ${ }^{4}$ Patients with elevation of troponin less than $5 \times$ the URL did not have a worse prognosis during follow-up. ${ }^{4}$ The identification of CAD patients at greatest risk of sustaining periprocedural myocardial injury (PMI) during PCI would allow targeted treatment with novel therapies capable of limiting the extent of PMI or reducing the number of patients with PMI.

\section{Mechanisms of myocardial injury during $P C l$ :}

PMI can result from procedural complications such as distal embolisation, side-branch occlusion (SBO), coronary dissection, disruption of collateral flow and silently after uneventful PCI procedures. ${ }^{2}$ PMI is classified into two types: Type 1 (proximal type), which is in proximity to the target lesion of PCI and may be due to SBO, and Type 2 (distal type), which is in the perfusion territory of the treated coronary artery and mainly due to structural and functional microvascular obstruction (MVO), ${ }^{2}$ Fifty to $75 \%$ of all the PMI is Type 2 (distal type), ${ }^{2}$

\section{Therapeutic strategies to prevent periprocedural myocardial injury:}

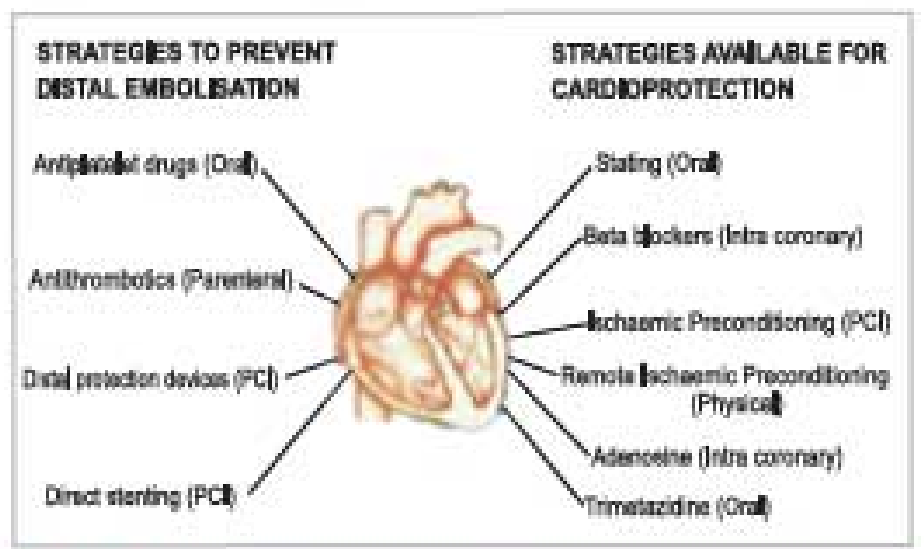

FIGURE 1 : Strategies to prevent PMI.

\section{Oral Antiplatelet Agents:}

\section{Aspirin}

Pretreatment with aspirin before PCI was associated with a decreased Incidence and significance of acute coronary thrombosis. ${ }^{5}$ Since then a relatively large, prospective study has shown that pretreatment with aspirin compared with placebo significantly reduces the incidence of transmural infarction during or soon after balloon angioplasty ( $9 \%$ vs, $1.6 \%), 6$ The CURRENT OASIS-7 trial performed in patients with acute coronary syndrome (ACS) scheduled for PCI showed no significant difference in ischaemic events or major bleeding when 'standard' dose daily aspirin (300-325 mg) was compared with low-dose aspirin $(75-100 \mathrm{mg})$. If patients are not taking maintenance aspirin or when there is doubt about drug compliance, a loading dose of $500-600 \mathrm{mg}$ orally should be given more than 3 $\mathrm{h}$ before PCI. ${ }^{7}$

\section{Clopidogrel}

Pretreatment with clopidogrel has been shown to provide dinical benefit in patients undergoing PCI for $\mathrm{ACS}^{8,9}$ and lack of clopidogrel pretreatment is independently associated with an increased rate of PMI. ${ }^{10}$ The ARMYDA-2 trial $^{11}$ proved that dopidogrel preloading with $600 \mathrm{mg}$ significantly reduces the rate of periprocedural MI compared with $300 \mathrm{mg}$ (administered $4-8 \mathrm{~h}$ before PCI). In the recent CURRENT OASIS-7 trial enrolling patients with ACS undergoing PCI, a loading dose of dopidogrel $600 \mathrm{mg}$ vs. $300 \mathrm{mg}$ followed by $150 \mathrm{mg}$ vs. $75 \mathrm{mg}$ daily for 1 month reduced cardiovascular death, MI and stroke by $15 \%$. This risk reduction comprised a $22 \%$ reduction in MI and a $42 \%$ reduction in the risk of definite stent thrombosis. Currently the ESC guidelines for PCI recommend early pretreatment with clopidogrel in patients who are scheduled for PCI ( $300 \mathrm{mg}$ at least $6 \mathrm{~h}$ before, or $600 \mathrm{mg}$ at least 2 $h$ before). It is dear that pretreatment with 600 $\mathrm{mg}$ is better than $300 \mathrm{mg}$ if PCI is intended in a short timeframe, but in stable elective patients presenting for ad hoc PCI, pretreatment remains debatable as some patients will not proceed to PCI. PRAGUE-8 suggests avoiding pretreatment before coronary angiography as this may save costs and reduce bleeding risk. 


\section{Prasugrel and Ticagre/or}

The novel thienopyridine, prasugrel, and ticagrelor, a novel non-thienopyridine ADP receptor blocker, have shown promising results compared with dopidogrel in patients with ACS $^{12,13}$ and prasugrel reduced periprocedural MI in patients with ACS $(4.9$ vs, $6.4 \%){ }^{14}$ As yet there is no evidence that these newer drugs are better in reducing PMI in elective PCI, but as patients with aspirin and/or dopidogrel resistance have worse clinical outcomes ${ }^{15,16}$ these newer antiplatelet agents with their enhanced and more predictable impact on platelet function could be beneficial.

\section{Intravenous Antithrombotic Agents:}

\section{Heparins}

Unfractionated heparin (UFH) has been used for decades to prevent thrombosis during $\mathrm{PCl}$ but there are no placebo-controled trials specifically examining its effectiveness. An intravenous bolus either under activated clotting time guidance or in a weight-adjusted manner is used.? Disadvantages of UFH include marked variability in bioavailability and as a consequence intravenous low-molecular weight heparin (LMWH) have been tested in the setting of elective or urgent $\mathrm{PCI}$. A meta-analysis of 13 trials induding 7318 patients showed that the use of intravenous LMWH during PCI reduces major bleeding but does not affect hard ischaemic end points in comparison with intravenous UFH. ${ }^{17}$

\section{Bivalirudin}

Direct thrombin inhibitors have been established in clinical practice in recent years and offer several advantages over UFH and LMWH (eg. establishing a more predictable anticoagulant response). The ISAR-REACT 3 trial performed in patients with stable and unstable angina who underwent $\mathrm{PCl}$ after pretreatment with clopidogrel showed that bivalirudin did not provide a net dinical benefit in comparison with UFH, but it did significantly reduce the incidence of major bleeding. ${ }^{18}$

\section{Glycoprotein IIb/IIIa antagonists}

The final step in the formation of thrombus is the binding of fibrinogen to the platelet glycoprotein IIb/IIIa receptor. ${ }^{19}$ The ISAR-REACT trial enroled patients undergoing elective $\mathrm{PCI}$, who were loaded with $600 \mathrm{mg}$ of clopidogrel, and found no benefit of additional abciximab.20 The ISARSWEET study performed in diabetic patients loaded with $600 \mathrm{mg}$ of dopidogrel undergoing elective PCI showed no benefit from additional abciximab. ${ }^{21}$ Before GPIs can be discarded in elective $\mathrm{PCI}$ several points need to be considered. First, in ISAR-REACT, pretreatment with $600 \mathrm{mg}$ of clopidogrel was done at a median of $7.4 \mathrm{~h}$ before PCI and GPIs might still have a role if ad hoc $\mathrm{PCI}$ is performed in patients without timely and adequate clopidogrel pretreatment. ${ }^{22}$ Second, it is important to note that despite pretreatment with aspirin and clopidogrel significantly lower troponin $T$ release was demonstrated in patients who additionally received GPIs. ${ }^{23}$ Similar results were shown for eptifibatide in the CLEAR PLATELETS study. ${ }^{24}$ In summary, discarding GPIs in all patients with stable CAD appears to be premature, GPIs continue to have a role in patients with ACS and elevated baseline troponin levels and in the case of threatening/actual vessel closure, visible thrombus or no/slow-reflow phenomenon. ${ }^{7}$ Additionally, GPIs might have a role in elective patients receiving multiple stents for complex anatomy and those who are not pretreated with clopidogrel at the time of $\mathrm{PCI}$ or have clopidogrel resistance. Prasugrel, ticagrelor or other newer more potent oral antiplatelet agents may further reduce the role of GPIs in stable patients.

\section{Other Drugs:}

\section{Statins}

Different retrospective trials and meta-analyses have suggested a reduction of PMI after elective $\mathrm{PCI}$ in patients who are pretreated with statins. ${ }^{25}$ The ARMYDA trial clearly demonstrated that pretreatment with $40 \mathrm{mg}$ of atorvastatin for 7 days markedly reduces the risk of PMI in patients who undergo elective $\mathrm{PCl}^{26} \mathrm{~A}$ recent study dearly demonstrated that a single dose of $80 \mathrm{mg}$ of atorvastatin before $\mathrm{PCI}$ reduces the incidenc 
of MI type $4 a_{-}{ }^{27}$ The ARMYDA-RECAPTURE trial showed that reloading patients who are already receiving statin treatment (application of $80 \mathrm{mg}$ of atorvastatin $>12$ h before the procedure and the application of an additional pre-procedural dose of $40 \mathrm{mg}$ ) markedly reduces the primary end point of cardiac death, MI or unplanned revascularisation at 30 days $(3.7 \%$ vs. $9.4 \%) .^{28}$ Statins are effective through different mechanisms. ${ }^{29}$ Treatment with a statin over 9 months can reduce fibrous-cap thickness of lipidrich plaques ${ }^{30}$ and this may explain why patients receiving chronic statin treatment present differently in ACS and why these patients experience less PMI during PCI. Besides plaque stabilisation, statins can improve endothelial function and have been shown to have antiinflammatory characteristics and reduce thrombogenic response.

\section{Calcium Antagonists}

Retrospective studies have suggested that pretreatment with calcium channel blockers reduces the incidence of PMI in patients undergoing elective PCI. ${ }^{31}$ Intracoronary nicardipine and verapamil have been successfully used in the treatment of no-reflow following PCI. Pretreatment with intragraft verapamil before PCI of saphenous vein grafts has been shown to reduce the rate of the no-reflow phenomenon but did not reduce PMI. ${ }^{32}$

\section{B-Blockers}

Benefit from $\beta$-receptor blockers in the reduction of myocardial necrosis has been suggested experimentally. ${ }^{33}$ Two randomised trials have analysed the role of intracoronary propranolol during PCl. ${ }^{34,35}$ Propranolol significantly reduced CK-MB, troponin $T$ and also clinical end points at 30 days. ${ }^{34}$ In a later study intracoronary propranolol administration significantly reduced PMI even in patients who received GPIs during PCI. ${ }^{35}$

\section{Trimetazidine}

Trimetazidine is a piperazine derivative antianginal drug with a vasodilatory effect on coronary arteries and has been extensively studied due to its additional cardioprotective preconditioning properties, ${ }^{36}$. The mechanism of cardioprotection by trimetazidine appears to be modulation of mitochondrial homeostasis downstream of the preconditioning pathway. One placebo controled, randomized, controlled trial involving 266 patients studied a loading dose of $60 \mathrm{mg}$ trimetazidine $30 \mathrm{~min}$ before recanalization. 37 This study showed significant reduction in postprocedural Troponin 1 levels in the trimetazidine group at all time points and also a significant reduction in the total Troponin I area under the curve.

\section{Non-Pharmacological Interventions in Prevention of PMI:}

\section{Myocardial Preconditioning}

Preconditioning using intracoronary administration of adenosine has been shown to decrease myocardial damage caused by elective $\mathrm{PCI}^{38}$ The use of nitroglycerin, nicorandil, bradykinin or enalaprilat has shown promising results (eg. reduction of ST segment shift, less chest pain) but reduction of PMI has not yet been demonstrated. Remote preconditioning induced by three $5 \mathrm{~min}$ inflations of a blood pressure cuff to $200 \mathrm{~mm} \mathrm{Hg}$ around the upper arm, followed by 5 min intervals of reperfusion, markedly improved the incidence of PMI in a recently published study and could represent an easily applicable tool to further reduce PMI during $\mathrm{PCl},{ }^{39}$

\section{CONCLUSIONS}

PMI is common after PCI. Periprocedural infarction (MI type 4a) occurs after PCI in at least $10 \%$ of cases and has an important impact on long-term prognosis. Measurement of biomarkers to allow assessment of PMI is an important tool for dinical and research purposes. Aspirin, clopidogrel and statins reduce PMI and patients scheduled for PCI should be pretreated with these drug5. LMWH and bivalirudin do not dearly show better ischaemic outcomes than UFH, and the latter continues to be used in many centres during elective PCI. GPIs should be considered in patients who are not pretreated with clopidogrel at the time of PCI, those with suspected or proven clopidogrel resistance or in 
patients with complex lesions who are expected to have a high prevalence of PMI. Newer oral antiplatelet agents such as prasugrel and ticagrelor have shown promising results in patients with ACS and future studies will show whether they will become a better alternative to dopidogrel in elective patients. Ischaemic preconditioning may receive more acceptance in the future as it is simple and inexpensive and could be effective.

\section{REFEREMCES}

1. Moschovitis A, Cook S, Meier B. Percutaneous coronary interventions in Europe in 2006. Eurolntervention 2010;6:189-94.

2. Herrmann 1. Peri-procedural myocardial injury: 2005 update. Eur Heart I 2005;26:2493-519.

3. Thygesen $K$, Appert JS, White HD. Third Universal definition of myocardial definition, Eur Heart 1 2012; 28:2525-38

4. Testa L, Van Gaal WJ. Myocardial infarction after percutaneous coronary intervention. QJM 2009;102: 369-78.

5. Barnathan ES, Taylor L. Aspirin and dipyridamole in the prevention of acute coronary thrombosis complicating coronary angioplasty. Ctculation 1987;76:125-34.

6. Schwartz L, Bourassa MG, Lesperance J, et al. Aspirin and dipyridamole in the prevention of restenosis after percutaneous transluminal coronary angioplasty. N Engl J Med 1988;318:1714-19.

7. Silber S, Albertsson P, Aviles FF, et at. Guidelines for percutaneous coronary interventions. the task force for percutaneous coronary interventions of the European society of cardiology. Eur Heart 3 2005;26: $804-47$.

8. Mehta SR, Yusuf S, Peters RJ, et al. Effects of pretreatment with dopidogrel and aspirin followed by long-term therapy in patients undergoing percutaneous coronary intervention: the PCI-CURE study, Lancet 2001;358:527-33.

9. Sabatine MS, Cannon CP, Gibson CM, et al. Effect of dopidogrel pretreatment before percutaneous coronary intervention in patients with ST-elevation myocardial infarction treated with fibrinolytics: the PCI-CLARITY study. JAMA 2005;294:1224-32.

10. Moore RK, Lowe R, Grayson AD, et al. A study comparing the incidence and predictors of creatine kinase $M B$ and troponin $T$ release after coronary angioplasty, does clopidogrel preloading reduce myocardial necrosis following elective percutaneous coronary intervention? Int J Cardiol 2007;116:93-7.

11. Patti $G$, Colonna G, Pascen V, et al. Randomized trial of high loading dose of clopidogrel for reduction of periprocedural myocardial infarction in patients undergoing coronary intervention: results from the
ARMYDA-2 (Antiplatelet therapy for Reduction of MYocardial Damage during Angioplasty) study. Circulation 2005;111:2099-106.

12. Wiviott SD, Braunwald E, McCabe $\mathrm{CH}$, et al. Prasugre versus dopidogrel in patients with acute coronary syndromes. $N$ Engl 3 Med 2007;357:2001-15.

13. Wallentin L, Becker RC, Budaj A, et al. Ticagrelor versus dopidogrel in patients with acute coronary syndromes. N Engl 3 Med 2009;361:1045-57.

14. Morrow DA, Wiviott SD, White HD, et al. Effect of the novel thienopyridine prasugrel compared with dopidogrel on spontaneous and procedural myocardial infarction in the trial to assess improvement in therapeutic outcomes by optimizing platelet inhibition with prasugrel-thrombolysis in myocardial infarction 38: an application of the dassification system from the universal definition of myocardial infarction. Circulation 2009;119:2758-64,

15. Snoep JD, Hovens MM, Ekkenboom JC, et al. Copidogred nonresponsiveness in patients undergoing percutaneous coronary intervention with stenting: a systematic review and meta-analysis. Am Heart 3 2007;154:221-31.

16. Lev EI, Patel RT, Maresh KJ, et af. Aspirin and clopidogrel drug response in patients undergoing percutaneous coronary intervention: the role of dual drug resistance. 1 Am Coll Cardiol 2006;47:27-33.

17. Dumaine R, Borentain M, Bertel 0 , et al, Intravenous low-molecular-weight heparins compared with unfractionated heparin in percutaneous coronary intervention: quantitative review of randomized trials. Arch Intern Med 2007;167:2423-30.

18. Kastrati A, Neumann FJ, Mehilli 1, et al. Bivalirudin versus unfractionated heparin during percutaneous coronary intervention. N Engl J Med 2008;359:688-96.

19. Anon Platelet glycoprotein IIb/1Hla receptor blockade and low-dose heparin during percutaneous coronary revascularization. the EPILOG investigators. N Engl 3 Med 1997;336:1689-96.

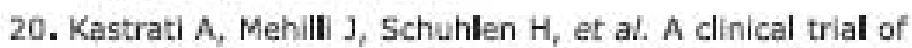
abciximab in elective percutaneous coronary intervention after pretreatment with clopidogrel. $N$ Engl 3 Med 2004;350;232-8.

21. Mehilli J, Kastrati A, Schuhlen $\mathrm{H}$, et al. Randomized clinical trial of abciximab in diabetic patients undergoing elective percutaneous coronary interventions after treatment with a high loading dose of dopidogrel. Circulation 2004;110:3627-35.

22. Gumina RJ, Yang EH, Sandhu GS, et al. Survival benefit with concomitant dopidogrel and glycoprotein $1 \mathrm{Ib} / \mathrm{IIl} a$ inhibitor therapy at ad hoc percutaneous coronary intervention, Mayo Clin Proc 2008;83:995-1001.

23. Bonz AW, Lengenfelder B, Strotmann 1, et al. Effect of additional temporary glycoprotein $\mathrm{ttb} / \mathrm{III}$ a receptor inhibition on troponin release in dective percutaneous coronary interventions after pretreatment with aspirin and clopidogrel (TOPSTAR trial). 1 Am Coll Cardiol $2002 ; 40 ; 662-8$. 
24. Gurbel PA, Bliden KP, Zaman KA, et af, Clopidogrd loading with eptifibatide to arrest the reactivity of platelets: results of the dopidogrel loading with eptifibatide to arrest the reactivity of platelets (CLEAR PLATELETS) study. Circulation 2005;111:1153-9.

25. Mulukutla SR, Marroquin OC, Smith C, et at. Effect of statin therapy prior to elective percutaneous coronary intervention on frequency of periprocedural myocardial injury. Am J Cardial 2004;94:1363-6.

26. Pasceri V, Patti G, Nusca $A$, et al. Randomized trial of atorvastatin for reduction of myocardial damage during coronary intervention: results from the ARMYOA (Atorvastatin for Reduction of MYocardial Damage during Angioplasty) study, Clrculation 2004;110:674-8,

27. Briguori C, Visconti G, Focaccio A, et af. Novel approaches for preventing or limiting events (Naples) II trial impact of a single high loading dose of atorvastatin on periprocedural myocardial infarction. I Am Coll Cardiol 2009;54:2157-63.

28. Di Sciascio G, Patti G, Pasceri V, et aL Efficacy of atorvastatin reload in patients on chronic statin therapy undergoing percutaneous coconary intervention: results of the ARMYDA-RECAPTURE (Atorvastatin for reduction of myocardial damage during angioplasty) randomized triaL J Am Call Cardial 2009;54:558-65.

29. Rosenson RS, Tangney CC. Antiatherothrombotic properties of statins: implications for cardiovascular event reduction. JAMA 1998;279:1643-50,

30. Takarada S, Imanishi T, Kubo T, et at. Effect of statin therapy on coronary fibrouscap thickness in patients with acute coronary syndrome: assessment by optical coherence tomography study. Atherosclerosis 2009;202: $491-7$.

31. Gulmez O, Atar I, Ozin B, et al. The effects of prior calcium channd blocker therapy on creatine kinase-MB lavels after percutaneous coronary interventions. Vasc Health Risk Manag 2008;4:1417-22.
32. Michaels AD, Appleby M, Otten MH, et al. Pretreatment with intragraft verapamil prior to percutaneous coronary intervention of saphenous vein graft lesions: results of the randomized, controlled vasodilator prevention on noreflow (VAPOR) trial I Invasive Cardiol 2002;14:299-302.

33. Reimer KA, Rasmussen MM, Jennings RB. Reduction by propranolal of myocardial necrosis following temporary coronary artery ocdusion in dogs. Circ Res 1973;33: 353-63.

34. Wang FW, Osman A, Otero J, et al. Distal myocardial protection during percutaneous coronary intervention with an intracoronary beta-blocker. Circulation 2003;107: 2914-19.

35. Uretsky BF, Birnbaum Y, Osman A, et al. Distal myocardial protection with intracoronary beta blocker when added to a Gp IIb/IIIa platelet receptor blocker during percutaneous coronary intervention improves dinical outcome. Catheter Cardiovasc Interv 2008;72:488-97.

36. Minners J, van den Bos EJ, Yelon DM, Schwalb H, Opie LH, Sack MN. Dinitrophenol, cyclosporin A, and trimetazidine modulate preconditioning in the isclated rat heart: support for a mitochondrial role in cardioprotection. Cardiovasc Res 2000;47:68-73.

37. Bonello L, Sbragia P, Amabile N, Com O, Pierre SV, Levy $S$, Paganeli F. Protective effect of an acute oral loading dose of trimetazidine on myocardial injury following percutaneous coronary intervention. Heart 2007;93: 703-707.

38. Desmet WJ, Dens J, Coussement P, et al. Does adenosine prevent myocardial micronecrosis following percutaneous coronary intervention? the ADELINE pilot trial. ADEnosine Limit myocardial Necrosis. Heart 2002;88:293-5.

39. Hoole SP, Heck PM, Sharples L, et af, Cardiac Remote Ischemic Preconditioning in Coronary Stenting (CRISP Stent) study: a prospective, randomized control trial. Circulation 2009;119:820-7. 